\title{
Cuerpo, racialización y performance en tiempos de multiculturalismo: sujeciones, agencias y subversiones en tres casos de patrimonialización afrolatinoamericanos
}

Viviana Parody ${ }^{1}$

\section{Resumen}

En las últimas décadas, en consonancia con el auge multicultural, los organismos internacionales comenzaron a tomar partido en defensa de la "diversidad" y de aquellas expresiones que de ella se derivan alcanzando el estatus de "patrimonio intangible" (UNESC0, 2003, 2005). En no pocas oportunidades, sin embargo, estas legitimaciones son adquiridas mediante arduos procesos de postulación en los que los Estados nacionales y los grupos "portadores" se ven involucrados en "inventarios" y "puestas en valor". Estos bienes culturales resultantes, cuyo clivaje es corporal, tanto pueden facilitar a sectores poblacionales históricamente subalternizados la subversión de estigmas como su reconfiguración en novedosas formas de otrerización -tales como exotismo, espectacularización, folklorización-. Entendiendo a estas convenciones y sus puestas en práctica como un tipo particular de política cultural de corte global que tiene su emergencia en el marco del multiculturalismo, en este artículo propongo dirimir -de manera comparativa y multisituada- las sujeciones, agencias y subversiones dadas en tres procesos de patrimonialización afrolatinoamericanos/caribeños (Colombia, Cuba, y Uruguay). De manera específica, analizo las articulaciones que entre raza, cuerpo y performance se suscitan en estos procesos mediante los cuales determinados sectores poblacionales signados por la "raza" devienen protagonistas y a la vez garantes de la "salvaguardia" de las expresiones performáticas patrimonializadas. En el transcurso, privilegio examinar la medida en que estas nuevas políticas de corte global (y sus traducciones locales), o bien fortalecen o bien ponen en cuestión "regímenes de corporalidad situados" (Restrepo, 2010). Una antropología dey desde los cuerpos asiste la metodología, en no pocos períodos circunscrita a la participación radical(Jackson, 1996 y Blacking, 1995 en Ferreira, 1999), donde la corporalidad del investigador se constituye en la materialidad especular sobre la cual los actores sociales también proyectan marcaciones e identificaciones contrastativas que, en no pocas oportunidades, aún responden a regímenes de colonialidad.

\section{Palabras clave}

Cuerpo. Racialización. Patrimonialización.

1 Doutoranda IDAES/UNSAM. Becaria doctoral CONICET-UBA, Argentina. E-mail: viviparody@yahoo.com.ar. 


\section{Abstract}

In recent decades, in line with the multicultural boom, international organizations began to take sides in defense of "diversity" and those expressions that derive from it, reaching the status of "intangible heritage" (UNESCO, 2003, 2005) . On many occasions, however, these legitimations are acquired through arduous application processes in which nation states and "carrier" groups are involved in "inventories" and "enhancements." These resulting cultural assets, whose cleavage is bodily, can both facilitate the subversion of stigmas to historically subalternized population sectors and their reconfiguration into novel forms of otrerization -such as exoticism, spectacularization, folklorization-. Understanding these conventions and their implementation as a particular type of cultural policy of a global nature that has its emergence within the framework of multiculturalism, in this article I propose to resolve - in a comparative and multisituation way the constraints, agencies and subversions given in three Afro-Latin American / Caribbean patrimonialization processes (Colombia, Cuba, and Uruguay). In a specific way, I analyze the articulations that between race, body and performance arise in these processes through which certain population sectors marked by "race" become protagonists and at the same time guarantors of the "safeguard" of patrimonialized performative expressions. In the course of this, it is my privilege to examine the extent to which these new global policies (and their local translations) either strengthen or call into question "situated corporeal regimes" (RESTREP0, 2010). An anthropology of and from bodies assists the methodology, in not a few periods circumscribed to radical participation (JACKSON, 1996 and BLACKING, 1995 in FERREIRA, 1999), where the corporality of the researcher is constituted in the specular materiality on which the actors Social organizations also project contrasting markings and identifications that, on many occasions, still respond to regimes of coloniality.

\section{Keywords}

Body. Racialization. Patrimonialization.

\section{Resumo}

Nas últimas décadas, em consonância com o boom multicultural, os organismos internacionais passaram a tomar partido na defesa da "diversidade" e das expressões que dela decorrem, atingindo o estatuto de "património imaterial" (UNESC0, 2003, 2005). Em muitas ocasiões, entretanto, essas legitimações são adquiridas por meio de árduos processos de aplicação, nos quais os Estados-nação e grupos de "transportadores" estão envolvidos em "inventários" e "aprimoramentos". Esses bens culturais resultantes, cuja clivagem é corporal, podem tanto facilitar a subversão de estigmas a setores historicamente subalternizados da população quanto sua reconfiguração em novas formas de terceirização - como exotismo, espetacularização, folclorização -. Compreendendo essas convenções e sua implementação como um tipo particular 
de política cultural de caráter global que tem sua emergência no âmbito do multiculturalismo, neste artigo me proponho a resolver - de forma comparativa e multisituacional - as subversões, agências e sujesões dadas em três processos de patrimonialização afro-latino-americana / caribenha (Colômbia, Cuba e Uruguai). De forma específica, analiso as articulações entre raça, corpo e performance surgidas nesse processo, por meio das quais determinados setores da população marcados por "raça" tornam-se protagonistas e ao mesmo tempo fiadores da "salvaguarda" das expressões performáticas patrimonializadas. No decorrer disso, tenho o privilégio de examinar em que medida essas novas políticas globais (e suas traduções locais) fortalecem ou questionam "regimes corporais situados" (RESTREP0, 2010). Uma antropologia dos e dos corpos auxilia a metodologia, em não poucos períodos circunscritos à participação radical (JACKSON, 1996 e BLACKING, 1995 em FERREIRA, 1999), onde a corporalidade do pesquisador se constitui na materialidade especular sobre a qual os atores. As organizações sociais também projetam marcações e identificações contrastantes que, em muitas ocasiões, ainda respondem a regimes de colonialidade.

\section{Palavras-chave}

Corpo. Racialização. Patrimonialização.

\section{Introducción}

Durante los últimos cien años, las américas y el caribe hispano se vieron interpelados por un sinfín de trabajos que abrigaron referir a sentidos racializados de existencia. En principio inspirados en el Harlem Renaissance ${ }^{2}$ o en el movimiento de la negritude ${ }^{3}$, escritores y activistas de nuestras latitudes fueron sumando sus propias narrativas (negristas o africanistas) nacionalmente situadas (GUILLÉN, 1931; CARPENTIER, 1933; ORTIZ, 1921,1924; ZAPATA OLIVELLA, 1963, 1983; PEREDA VALDÉS, 1937, 1965; CARÁMBULA, 1966; ORTIZ ODERIGO; 1969, 1968). Asimismo, en el ámbito académico, tras la iniciativa de Melville Herskovits ${ }^{4}(1928,1941,1966$ [1945]) y la impronta de

\footnotetext{
2 Me refiero al movimiento artístico y contracultural "del renacer del arte negro" dado en Harlem (Nueva York) hacia la década de 1920.

${ }^{3}$ Con el término negritud hago referencia al movimiento desarrollado entre aproximadamente 1930 y 1960 desde las universidades del primer mundo por estudiantes negros pertenecientes a la élite de las colonias francesas (como el martiniqués Aimé Césaire y el senegalés Léopold Senghor, entre otros).

${ }^{4}$ En 1941 y 1942 el antropólogo cultural norteamericano trabajó en Brasil. Estos desempeños bien pueden dar cuenta de la difusión de sus trabajos, de cuyos alcances se tomarán diversos
} 
Roger Bastide $^{5}$ (1935, 1947, 1958), diversos cientistas latinoamericanos fueron articulando su labor consiguiendo en algunos casos horadar el imaginario nacional europeizado con nuevos o antiguos discursos de los que se derivaron algunos efectos de verdad respecto del ser negros/as (FRIEDEMANN, 1979, 1983, 1984; AROCHA, 1999; FRIEDEMANN Y AROCHA, 1982; ZAPATA OLIVELLA, 1967, 1977; ORTIZ, 1985 [1951], 2015; CARVALHO NETO, 1955, 1971; AYESTARÁN, 1953, 1967; entre otros).

Continuamente reactualizados, y a la vez siempre cargados de sentidos diaspóricos, estos discursos supieron tanto reflejar el caudal simbólicoexpresivo de las distintas experiencias y ontologías afrolatinoamericanas, como a la vez colaborar en su (re)configuración afectando trayectorias afrodescendientes/negras situadas y concretas (PARODY, 2017 b) ${ }^{6}{ }^{-}$. Por su parte, las performances afrolatinoamericanas dieron encarnadura a estos procesos para los cuales la modernidad funcionó como condición de posibilidad. En afinidad con la dialéctica de oposición binaria que la modernidad/colonialidad dejó habilitada (civilización/barbarie), dichas performances asumieron la contra-imagen especular del sí mismo europeo con el que los Estados nacionales latinoamericanos y caribeños se establecieron.

Cuando en la actualidad diversos organismos multilaterales ocupan su destino en la realización de un archivo de "danzas, músicas y cantos afrodescendientes", no hacen más que invitar a los países miembros al (feliz u obligado) registro audiovisual de dicho capital performático al que suponen como claramente ubicable, nacionalmente inscripto (como "afrocolombiano", "afrocubano" o "afrouruguayo") e históricamente sedimentado (aun cuando se trate de procesos de retradicionalización contemporáneos). Se fijan así, en nombre del reconocimiento, pedagogías de la diferencia previamente culturalizada (RESTREPO, 2004), a la vez que repertorios de memoria (TAYLOR, 2015) que conservan en su núcleo la doble posibilidad de reproducir/subvertir el régimen de modernidad/colonialidad que los vio nacer.

antropólogos colombianos de la talla de Jaime Arocha y Nina Friedemann.

${ }^{5}$ Entre 1938 y 1951 coincidió en desempeñarse como sociólogo en la Universidad de San Pablo, para volver a radicarse en Francia en 1958 y dedicarse a la etnología religiosa. De sus trabajos en relación a la población afrobrasileña se hereda el concepto de aculturación.

${ }^{6}$ He dado cuenta de este proceso para el caso uruguayo, es decir de cuánto las obras literarias de los folkloristas o cientistas retroalimentan las performances de la cultura popular negra décadas después de ser publicadas. Aquí el fetichismo radica en que, entre los grupos performáticos correspondientes con una cultura popular negra, los elementos reapropiados de estas fuentes (y resignificados) se internalizan para ser definidos como "tradicionales" (cultivados desde tiempos inmemoriales, y/o directamente ancestrales). Esto no invalida éstos ni otros procesos. 
Teniendo en cuenta los debates ya dados en el campo de la antropología y los estudios culturales (RESTREPO, 2012; STUART HALL, 2010), en el presente artículo busco profundizar respecto de los procesos de marcación y desmarcación que los grupos llevan adelante en y a partir de estas prácticas corporalizadas en tanto en las mismas resultan asumidas identificaciones étnico-raciales y sexo-genéricas, e inscripciones de nacionalidad y subalternidad. Por medio de la presentación de tres casos nacionales correspondientes con expresiones afrolatinoamericanas patrimonializadas, adelanto algunas elaboraciones de la investigación doctoral en curso para poder dirimir las sujeciones, agencias y subversiones que los colectivos afrodescendientes ejercen desde la corporalidad (RODRÍGUEZ, 2010) y/o en el cuerpo como lugar (HANNERZ, 1998 en PARODY, 2016). En tanto la metodología de abordaje reviste las características de participación radical (JACKSON, 1996 Y BLACKING, 1995 EN FERREIRA, 1999) e investigación en/desde los cuerpos $^{7}$ (CITRO et al, 2020), el imaginario racializado (CAGGIANO, 2015) ${ }^{8}$ que se desprende de los procesos que he descripto resulta proyectado en las interacciones sociales dadas a lo largo del proyecto de investigación. Esto se observa sobre todo así, principalmente, durante los períodos de corresidencia (llevados adelante entre grupos afrodescendientes de Cuba, Colombia y Uruguay), aunque también durante la pandemia bajo las características de la netnografía (o etnografía digital y de los medios digitales de los grupos). Es en el marco de estas interacciones etnográficas que puedo definirme como mujer socialmente blanca, condición racializada a la que mucho aporta la labor de investigadora o "académica", lo que en cada contexto nacional también varía en modalidad de percepción y relevancia. Con la idea de racialización me estaré refiriendo "a ese proceso de marcación-constitución de diferencias" que es traducido en jerarquías sociales a partir de diacríticos biologizados y que con frecuencia derivan en la gubernamentalización de la existencia (ARIAS Y RESTREPO, 2010, p. 58).

En tanto las definiciones de raza/racialización resultan siempre dialógicas y situadas (DE LA CADENA, 2008 en CAGGIANO, 2015), la compresión de

\footnotetext{
7 Como afirman las autoras, estas metodologías posibilitan formas de comunicación no verbal y de "reflexividad corporizada" que favorecen la ubicación de violencias silenciadas e invisibilizadas así como las agentividades que pueden vehiculizar su transformación.

8 Reconociendo los aportes de la perspectiva decolonial a esta problemática, Caggiano (2015) advierte sobre los riesgos de lo que presenta como una "deriva decolonial esencialista", que se origina en encontrar el sustrato de la raza no ya en la biología o en la cultura, sino en una comprensión esencializada de la historia.
} 
sus formas concretas siempre requiere profundizar las particularidades dadas en los diferentes contextos, y los casos en estudio nos permiten en este trabajo dar cuenta de cómo estas heterogeneidades son vividas y aprendidas performáticamente. Parto para ello de un concepto amplio de performance que no solo remite a la práctica de músicas y danzas sino a todo hecho social que pueda ser analizado como tal (SCHECHNER, 2000). Para Víctor Turner (2002), son válidos dos tipos de performances: las de tipo social o performance social, $\mathrm{y}$ aquellas que abarcan el campo de lo estético y las "puestas en escena" y que denomina como performances culturales. Varios casos a los que haré mención confluyen en ambas categorizaciones. Finalmente, en tanto los estudios de performances se distinguen de la teoría de la performatividad (BUTLER, 2005, 2007), me serviré también de esta última perspectiva para entender como el género, la raza, la clase social y la religiosidad se articulan en cada caso nacional produciendo maneras corporeizadas, permitidas o esperables de ser afrocubanos, afrocolombianos/palenqueros, o afrouruguayxs.

\section{“Un rincón de África en Colombia" como modelo de "economía naranja"}

San Basilio de Palenque es un poblado rural que ha sido fundado por esclavizados cimarrones que huyeron de Cartagena a fines del siglo XVII, por lo que suele ser definido como "el primer pueblo libre de América" ${ }^{9}$. Ubicado a los pies de los Montes de María (Departamento de Bolívar), a unas tres horas de Cartagena de Indias (Colombia), San Basilio resulta un caso emblemático del "patrimonio intangible" pues las y los palenqueros mantienen una lengua creole (la "lengua palenquera"), cantos y ritos funerarios denominados como lumbalú, y un sistema de organización social basado en grupos de edad o kuagros, razón por la que también le vale ser nombrado como "el último rincón de África en Colombia". Organismos internacionales como la UNESCO, el Banco Mundial o la ONU, entre otros, saben tener presencia en este sitio privilegiado que ha oficiado de laboratorio patrimonial por tratarse de uno de los primeros "espacios culturales" con este tipo de reconocimiento en América Latina y el Caribe.

\footnotetext{
${ }^{9}$ Gracias a los atributos otorgados por la Ley 70 de 1993 (aquella que en Colombia instrumenta el artículo de la Constitución Nacional de 1991 referido a las "comunidades negras") cuenta con un Consejo Comunitario renovable cada dos años y titulación colectiva de las tierras.
} 
Según la UNESCO, el "Espacio Cultural de Palenque de San Basilio" se encuentra "amenazado no sólo por los cambios económicos que afectan a los modos de producción locales, sino también por el conflicto armado dado entre los paramilitares colombianos y grupos guerrilleros locales" ${ }^{10}$. El organismo multilateral, también ubica en la discriminación racial -que las y los palenqueros sufren fuera de su poblado- el origen del rechazo que los propios palenqueros y palenqueras han tenido respecto de "sus valores culturales", lo que habría generado no solo la necesidad de la patrimonialización sino, muy previo a la misma (1986), la modalidad de Educación Intercultural Bilingüe (y agraria) para su (única) escuela ${ }^{11}$. La reversibilidad del estigma que históricamente acaecía sobre la lengua palenquera es producto de estas agencias que la propia comunidad palenquera pudo estimar llevar adelante en diálogo (o no) con los organismos nacionales e internacionales, aunque siempre en alianza con determinados sectores académicos ${ }^{12}$.

Estos procesos de índole patrimonial, contrastan muchas veces con las dificultades diarias de las familias palenqueras, cuyas resoluciones se derivan en las mujeres. Siendo San Basilio de Palenque un poblado rural cuya economía de base agraria se encuentra absolutamente vital, a la vez que en transición hacia las economías sociales de tipo urbanas, la división sexual del trabajo se sigue presentando con todos estos disímiles ribetes. Siendo escasos los puestos de trabajo para los crecientes palenqueros/as profesionalizados, los desempeños mayoritarios se definen entre lo agrario (con prevalencia masculina) y lo urbano (con prevalencia de mujeres y de jóvenes). Convocadas al circuito turístico cartagenero (CUNIN, 2006), las mujeres palenqueras ofrecen sus productos con sus trajes típicos en continuidad con la metáfora colonial. Como analizan Valle y Martínez (2018), cuando los diacríticos culturales se escriben sobre el cuerpo de las mujeres estos pueden terminar oficiando de meros soportes. Sobre los mismos, la indumentaria se despliega como máscara, pues el cuerpo es dispuesto como territorio de la imagen

\footnotetext{
${ }^{10}$ Esto ha sido así hasta bien entrados los años 2000, y la patrimonialización en gran medida estuvo motivada en esta situación (colocar una mirada internacional en el poblado para impedir mayores masacres).

${ }^{11}$ Este ha sido un proceso sobre todo impulsado por Dorina Hernández, palenquera doctoranda en Ciencias de la Educación (Universidad de Cartagena), partícipe del PCN / Proceso de Comunidades Negras (Regional Palenque "KU SUTO" Caribe, 1992-2009) y del Movimiento Nacional Cimarrón (1987-1991).

12 Es en primer lugar la etnolingüística la que ha tenido mayor presencia, tras la obra Lengua y Sociedad en el Palenque de San Basilio de Nina Friedemann (1983).
} 
(MATOSO, 2001). Esta performance ${ }^{13}$ mediante la cual las vendedoras de dulces oriundas de San Basilio de Palenque actúan a la mujer palenquera, permiten que en un espacio de interacciones sociales signadas por el consumo (tal como es el turismo) el valor de uso se extienda desde el producto hacia su emblema fetichizado ${ }^{14}$, situación en la cual la etnicidad opera como valor de cambio (COMAROFF \& COMAROFF, 2011).

Como pobladoras rurales, son muchas veces estas mismas mujeres las que llevan adelante reclamos en pos de la subsistencia o la pavimentación del poblado, siendo éstas necesidades que en todos los casos se ubican "por fuera de la cultura", y suelen ser respondidas mayormente por fundaciones y corporaciones -y en menor o nula medida por el Estado-. El mismo circuito turístico que las acoge, desde la patrimonialización se ha extendido en sentido inverso -esto es, desde Cartagena hacia San Basilio de Palenque- dando lugar a la proliferación de propuestas de etnoturismo. Estas posibilitan que, en pleno COVID 19, mujeres palenqueras expertas en productos culinarios tradicionales didacticen sus recetas mediante workshops organizados por ONGs transnacionales ${ }^{15}$. En estas clases o workshops, que dan cuenta de los niveles de formalización de las prácticas económicas de las mujeres palenqueras -y no solamente de la injerencia de las ONGs-, estas mujeres convierten su cocina rural en una escena in situ y facilitan su corporalidad mediada por la indumentaria para una situación especular ${ }^{16}$ o de alteridad radical. El uso común alusivo de los colores de la bandera colombiana proyectados en sus vestuarios también metaforiza la situación contemporánea de integración (social y económica) que las mujeres palenqueras registran en relación con la sociedad nacional colombiana.

Entre 2008, en que se formaliza la inscripción de San Basilio como "espacio cultural", y la actualidad, puede constatarse también la inauguración de la Casa de la Cultura palenquera, y el traslado de los talleres de danzas para niñas y

\footnotetext{
${ }^{13}$ Schechner (2000) nos mencionaba que todo hecho social puede ser analizado como performances. A la vez, para Víctor Turner (2002) son válidos dos tipos de performances que él mismo define como performance social, y aquello que define como performance cultural (el campo de lo estético y las "puestas en escena").

${ }^{14} \mathrm{El}$ producto puede tener una doble fuente de valor agregado al ser artesanal pero, a la vez, "étnico".

${ }^{15}$ En el ejemplo dado ha intervenido la fundación ACUA (Activos Culturales Afro). Ver las características y estándares éticos de la Fundación ACUA en: https:/ / programaacua.org/

${ }^{16}$ Vuelvo a referir al acto de identificación/distinción que se produce cuando el sí mismo de quien consume (generalmente sectores de clase media blancos aunque no únicamente) es percibido como contrapuesto o distante de la alteridad que el performer hace manifiesta.
} 
niños desde las casas de los propios pobladores y familias "portadoras" hacia este predio cultural sustentado por la propia UNESCO. Esto es así en desmérito de la asistencia diaria y masiva de las y los niños palenqueros a los juegos de la plaza central que fueron destituidos para la edificación de un escenario y un playón que se utilizan privilegiadamente los primeros días de octubre para el Festival de Tambores y Expresiones Culturales de Palenque. Según el propio consejo comunitario $^{17}$ y algunos etnoeducadores con desempeño en el poblado, el festival cobró características espectacularizantes desde la patrimonialización, muy a pesar de haber sido iniciado por un maestro de escuela hace más de treinta años con otro tipo de características que también colocaban a los niños en lugar de privilegio. Desde sus inicios, el festival se realiza para las conmemoraciones del 12 de octubre, fecha que para entonces (previo al multiculturalismo colombiano) celebraba "la raza hispánica". Sobre dicha efeméride eurocentrada, y como acción etnoeducativa, el festival de entonces introducía a las y los niños en el aprendizaje formal de sus danzas (como el mapalé), otorgando reconocimiento a las mismas y a los grupos participantes. La vasta trayectoria de décadas de realización de este festival nos muestra la medida en la que una misma propuesta puede, según contexto, tanto favorecer los procesos de agencia como recrudecer las sujeciones.

A pesar de las lógicas más folklorizadas o espectacularizadas que a veces se imprimen en el Festival de Tambores y Expresiones Culturales de San Basilio de Palenque, durante el mismo también tienen lugar instancias de debate regional e internacional. Organizadas en la Casa de la Cultura palenquera, a donde espontáneamente se dan cita diferentes referentes académicos y políticos -como Agustín Lao Montes o Sheyla Walker, entre otros ${ }^{18}{ }_{-}$, estas mesas de debate transcurren en paralelo con las dinámicas de música y danza (locales y foráneas) alojadas en el nuevo escenario del playón de la plaza. En esta dinámica es clara aquella lógica descripta por Cunha (2001) cuando refiere a trayectorias o bien culturalistas o bien politizadas de los grupos afrodescendientes pues en estas dinámicas parecieran manifestarse dos circuitos bien diferenciados: el que podemos denominar como más

\footnotetext{
17 En 2010, el director del Programa Afrodescendientes del Ministerio de Cultura argentino, Javier Ortuño, entró en diálogo con el Consejo Comunitario de San Basilio de Palenque, y hacia entonces este organismo comunitario mantenía cierta diferencia de perspectiva con la corporación que dirigía el festival. Pude constatar esto en San Basilio en 2011, lo que no significa que estas diferencias se mantengan en todo momento y lugar entre todos los consejos comunitarios en ejercicio y las diferentes directivas que haya tenido el festival.
}

${ }^{18}$ He compartido dicho espacio en 2016 durante el trabajo de campo. 
correspondiente con una "cultura popular negra"19 que de manera recreativa asiste al festival, y el que podemos ubicar en los debates que se realizan en el marco de la Casa de la Cultura. La feria artesanal de productos aledaña al escenario (que es ubicado en la plaza) se constituye, en este sentido, en un ámbito de transición en el que tanto se pueden adquirir productos como reivindicar estéticas. Es el turista extranjero el que articula estos tres ámbitos con su recorrido, ligando con sus cuerpos en circulación la distancia material y simbólica existente entre estas actividades o circuitos, aun cuando no alcanzan una lectura comprensiva en ninguno de ellos dada la falta de códigos socioculturales compartidos. Con la adquisición de trenzados o productos, sin embargo, los turistas pueden salvar estas distancias y "llevarse" al palenque inscripto en el cuerpo.

La plaza de San Basilio que aloja al festival y que cumple con las características de ser la plaza de un poblado semi-rural frente a la cual se ubica su pequeño centro de salud y la iglesia, en el año 2001 ha sido testigo del asesinato de tres jóvenes palenqueros masacrados "por sospecha de guerrilla". Entre las gigantografías del playón que hoy denotan la "cultura palenquera" no existe ninguna señalización que mantenga la memoria de estos hechos vinculados al conflicto armado, que son los que originalmente dieron motivo a agentes académicos y comunitarios para pensar en la postulación de San Basilio de Palenque a la Lista Representativa del Patrimonio Intangible. Tras la nueva infraestructura, la plaza del pueblo de San Basilio dio lugar a la acogida de Iván Duque Márquez, presidente de Colombia, quien en 2019 afirmó al visitar las diferentes instituciones del poblado:

\footnotetext{
“Yo quiero que San Basilio de Palenque sea un área de desarrollo naranja, como lo llamamos en el Plan de Desarrollo. Un área de desarrollo cultural, que todos los colombianos en el Bicentenario conozcamos la historia de esta comunidad para sentirnos más orgullosos de ser colombianos. Ese es el orgullo que ustedes representan para mí" (Iván Duque Márquez, 11 de Abril de 2019, San Basilio de Palenque) ${ }^{20}$.
}

Las retóricas del reconocimiento se articulan, de esta manera, a las lógicas de un tipo de "desarrollo" para el que "la cultura" representa la posibilidad de

\footnotetext{
${ }^{19}$ Sigo a Stuart Hall en el uso de éstos términos.

${ }^{20}$ En 2021 se cumplen los 200 años de la creación de La Gran Colombia, república creada diez años después de la independencia en base a la articulación de los territorios de Colombia, Panamá, Venezuela y Ecuador.
} 
ingreso económico frente a un sistema redistributivo racista. En 2015 San Basilio cumplió con el "Plan de Salvaguardia" iniciado en 2005. Durante este período, el "etnoturismo" se alistó entre las principales posibilidades de sustentabilidad económica más comunes del poblado, las corporaciones (asociaciones con personería jurídica) se triplicaron, y todo cuanto se hubo registrado ha sido producido "de Palenque para el mundo" -y en menor medida para responder a las necesidades de la propia comunidad-. Como contraparte, el Consejo Comunitario y las agrupaciones juveniles, llevaron adelante tareas de saneamiento -aún en pleno COVID 19-, e incluso protestas frente a la prohibición de circulación y venta ambulante, o la falta de cumplimiento del presidente Iván Duque respecto de un Plan Integral de "desarrollo" para San Basilio de Palenque que incluiría la construcción de instituciones deportivo-recreativas aún sin concreción.

Contra toda retórica tradicionalista, aunque de la mano de esencialismos y agencias, en San Basilio conviven prácticas de rap y reggaetón junto al bullerengue y el mapalé, el lumbalú o el son de negro y asimismo la champeta, músicas todas equitativamente atravesadas por el desarrollo de una industria cultural de mediana escala que duplica la posibilidad de visibilización de las y los palenqueros en los términos descriptos (vitrina para el mundo). Palenque Records, un sello discográfico independiente con sede en Colombia y Francia, fue creado en 1997 por Lucas Silva y está dedicado a la producción de films y discos sobre la música tradicional afrocolombiana. Grandes tocadores y cantadoras de San Basilio de Palenque fueron grabados in situ por Palenque Records para fonogramas y audiovisuales que han estado principalmente dirigidos "a los propios" ${ }^{21}$, posibilitando -paradójicamente- a las y los palenqueros de una generación "tradicional" recuperar la liminalidad que la espectacularización y el turismo "étnico" habían trocado en valor de cambio. Según Richard Schechner (1985), la transición en el ritual es alcanzada tras los momentos de caldeamiento o preparación, asistencia al mundo liminal o performático, y retorno a la cotidianeidad. En los materiales audiovisuales (o emisiones radiales), según condiciones de producción, pueden verse estas mismas características que gracias al efecto de "vitrina" han tendido a dejarse de lado en las prácticas corporalizadas que son regladas por el espectáculo.

\footnotetext{
${ }^{21}$ Su primer documental "Los Reyes Criollos de la Champeta" (La Huit Production, Paris 1998), dio a conocer la champeta criolla al mundo. En homenaje a Paulino Salgado "Batata", y otros músicos célebres de San Basilio de Palenque, en el año 2000 Lucas Silva realiza "Los Hijos de Benkos" (Les Films du Village-Rfo-Mezzo), y durante el rodaje trabaja y graba junto a todos los grupos musicales de Palenque, entre ellos Las Alegres Ambulancias y el Sexteto Tabalá.
} 
Sobre todo se trata, en este tipo de producciones audiovisuales que tienden al rencuentro comunitario e intergeneracional en un marco de no espectacularidad, de un proceso acontecido por y para los partícipes, lo que se vuelve absolutamente lejano a las lógicas binarias de "hacedores" vs "público espectador" que son propias de la espectacularización. Medios y mediaciones tampoco se presentan entonces en correspondencia con modernidad o tradición.

Dentro de tales lógicas y con las mediaciones que hoy incorporan las nuevas tecnologías -es decir, sin la necesidad de recurrir a un sello fonográfico- el grupo Kombilesa $\mathrm{Mi}^{22}$ creó un nuevo género musical al que denominan como RFP (rap folclórico palenquero) mediante el cual narran en lengua palenquera la historia cultural del poblado, "representan sus vivencias cotidianas", "fortalecen las tradiciones musicales de San Basilio y la lengua palenquera", a la vez que "fortalecen y le dan mucho más cuerpo al tema del rap en San Basilio" $^{23}$. Las performances sonoras, danzarias y audiovisuales de Kombilesa Mi, operan a la manera de actos de habla o enunciados realizativos o performativos (AUSTIN, 1956, 1962; Searle, 1990 [1969]): al paso del grupo de rap folklórico por el pueblo, los niños responden con vocablos "en lengua", reduciendo las distancias entre "lo que la gente dice y lo que la gente" pues, en este tipo de prácticas de reivindicación, las palabras hacen cuando crean realidades (PEIRANO, 2001). Inserto en las redes sociales y el consumo cultural que es propio de la industria, el grupo también aspira a "llevar a San Basilio de Palenque a un Grammy Latino" y convertirse de esta manera en un nuevo orgullo palenquero, quizás tanto como lo fue Kid Pambelé, el campeón mundial de boxeo Antonio Cervantes Reyes (1972), quien no solo "trajo la luz eléctrica a su pueblo" sino que "le enseño a ganar a Colombia" frente al mundo. ¿Será que, mediante un Grammy, Kombilesa Mi pueda hacer extensiva la red de internet para San Basilio de Palenque, prácticamente incomunicado en pleno COVID 19 ?.

22 En lengua palenquera significa "mis amigos", y remite al kuagro de edad.

${ }^{23}$ Julio Andris Padilla, director del grupo en 2016, para el diario El Espectador, Colombia. 


\section{De capitalismo, comunismo y después (de la revolución cubana)}

Frente a este caso emblemático (afro)colombiano, podemos ubicar en segundo lugar el caso cubano. A diferencia de como ocurre en el multiculturalismo colombiano con la prominencia de los "grupos étnicos" como garantes de "diversidad" (AROCHA, 2004; AGUDELO, 2005, 2019; BOCAREJO Y RESTREPO, 2011; CHÁVEZ, 2011), en Cuba aún prevalece la tensión entre resaltar $v s$ desacreditar la "afrocubanía" reivindicada por Alejo Carpentier. La noción de "transculturación", en cambio, impulsada por Fernando Ortiz en Contrapunto del tabaco y del azúcar, es abrigada por organismos estatales y por el común de la población cubana como metáfora del mestizaje. Dado el contexto socialista donde "todos son iguales ante la ley", se sostendría que en Cuba no existen diferencias signadas por la "raza" (VOLPATO PERBELLINI, 2008; MORALES DOMÍNGUEZ, 2002). Sin embargo, esta posición no ha derivado en la erradicación del racismo estructural que también alcanza a la isla (CASTRO, 1959, 2001; MANZANARES BLANCO, 2020). Cuba tiene, además, una institución referencial para las "Américas negras" como es Casa de África de La Habana, y una serie incipiente de proyectos de base étnico-racial llevados adelante por la propia población cubana -ávida de promover recursos, pero también de reformular su realidad-. Diversos desafíos se vienen enunciando en esta clave más recientemente (CAMPOALEGRE SEPTIEN, 2019 a, 2019 b), a la vez que referentes de la academia cubana se insertaron en un área de estudios "afrolatinoamericanos" correspondiente primeramente con la Universidad de Harvard (DE LA FUENTE \& ANDREWS, 2018), y más recientemente en un área de estudios afrodescendientes que se corresponde con el Consejo Latinoamericano de Ciencias Sociales CLACSO (CAMPOALEGRE SEPTIEN, 2019 a, 2019 b).

Es en este contexto de transición de un socialismo ortodoxo hacia una mayor apertura (de capitales) que la rumba es inscripta en la Lista Representativa del Patrimonio Cultural Inmaterial de la UNESCO, días posteriores al fallecimiento de Fidel Castro acontecido en noviembre de 2016. En un proceso clave de la historia de Cuba como es la reforma constitucional, un plan de incipiente "apertura al mundo" que implica tanto la "lucha contra el bloqueo" norteamericano (aún vigente) como la paulatina dolarización de su sistema monetario, la doble exposición de la rumba para un circuito turístico hotelero de alta gama y un circuito "etnoturístico" más comunal, muestra también las vicisitudes del "patrimonio inmaterial". Este marco de aperturas, que también incluye el incremento en el ingreso de los capitales extranjeros y el paulatino 
proceso de gentrificación urbana (dado tras la puesta en valor del casco histórico de La Habana Vieja), presenta lógicas racializadas disímiles a las colombianas, y tendencias institucionales en oposición en relación con la "cubanía" o la "afrocubanía" que Casa de las Américas (entre otras instituciones) en diversas oportunidades ha dado en dirimir (ALÉN, 2016) ${ }^{24}$. En el marco de estas lógicas sobre las que se debate la racialización en Cuba, y no a contrapelo de ello, es que más recientemente han comenzado a introducirse retóricas multiculturales o multiculturalistas (CAMPOALEGRE SEPTIEN, 2019 b).

En relación con la patrimonialización en cuestión en este caso nacional, en su estrategia enunciativa la UNESCO (es decir, Cuba en su postulación) define a la rumba "cubana" como la "mezcla festiva de baile y música, y todas las prácticas culturales inherentes", aunque hace clara mención a "la música y los movimientos de la rumba de Cuba [como] esencialmente vinculados a la cultura africana, pero también [a] elementos característicos de la cultura antillana y el flamenco español" (UNESCO, 2016) ${ }^{25}$. En sus documentos de postulación, se apela a la "integración cultural" tricontinental, se define a la rumba como "la forma más auténtica de consolidación de la nación cubana", y se apela a "la internacionalización de su lenguaje" ${ }^{26}$.

El evento que permite la difusión de la expresión por toda la isla -el Festival Timbalaye o Ruta de la Rumba- es prexistente a esta inscripción, y se encuentra coordinado por los mismos artistas cubanos que llevaron adelante la postulación de esta expresión performática frente a UNESCO, con el apoyo del Estado cubano $^{27}$, aunque residiendo en el extranjero. Mayoritariamente, la Ruta de la Rumba, cumple con todas las características que emanan del turismo cultural: es un tipo de oferta turística que convoca tanto a académicos como amantes de la cultura, a embajadores e interesados en general, y que a la vez deviene en emprendimiento para estos artistas que operan triangularmente entre Cuba, México e Italia como opción estratégica frente a la imposibilidad

\footnotetext{
${ }^{24}$ La conferencia de cierre de Olavo Alén argumentó la inconveniencia de la utilización del prefijo "afro" en relación con la procedencia de las músicas cubanas como el son.

${ }^{25}$ Cuba tiene en total cuatro elementos inscritos en la lista representativa del Patrimonio Cultural Inmaterial de la Humanidad de la UNESCO: la tumba francesa, la rumba, el punto cubano y la parranda de San Pedro.

${ }^{26}$ Ulises Mora Valiña, reconocido cultor de esta expresión, preside el consentimiento comunitario que es acompañado de un total de 270 firmas.

${ }^{27}$ Usualmente el proceso es inverso: las autoridades estatales dirigen la postulación y convocan a los referentes comunitarios para el consentimiento y la posterior instrumentalización. En todos los casos o modelos de gestión, es el Estado el que recibe los fondos económicos para garantizar la "salvaguardia" de la expresión en cuestión.
} 
de constituir personerías jurídicas en Cuba. El estatuto económico cubano en este caso inhibe a los ciudadanos del gerenciamiento directo de capitales extranjeros o globales vía ONGs, con lo cual el rol del Estado en materia de economía política en Cuba presenta una caracterización única. Todo nos llevaría a pensar que entonces, bajo este tipo de regímenes proteccionistas y estatistas, las lógicas del capital no tendrían ingreso. Sin embargo, de la mano del turismo -y, llamativamente, de manera similar a como ocurre en Cartagena, en los últimos años en Cuba se han desarrollado prácticas -de alta, media o baja intensidad- que en su configuración viabilizan procesos de subjetivación similares a los dados bajo la proliferación del "desarrollo" en clave de "economía naranja" ${ }^{28}$. Utilizo las categorías de alta, media o baja intensidad para poder referir a aquellos micro proyectos de base comunitaria que tienden a dar respuesta a la subsistencia familiar, diferenciándolos de economías de tipo industrializadas como las grandes cadenas hoteleras y/o las empresas transnacionales de turismo.

A pesar de su articulación a un circuito menor del turismo cultural internacional, la Ruta de la Rumba garantiza desde hace más de una década la movilidad imprescindible para el encuentro de referentes afrocubanos mayores reconocidos en esta práctica a lo largo de toda la isla. Las performances se realizan con la presencia de un turismo (europeo) de baja intensidad, y una amplísima participación comunitaria que incluye el despliegue de la liturgia ritualístico-religiosa correspondiente con la Regla de Ocha e Ifá que para el turista permanece velada tras los cantos y danzas de rumba que son dedicados a los orishas. En su mayoría, los partícipes de la performance sonoro-danzariacantada son afrodescendientes socialmente negros que saben reservar el secreto del yambú ${ }^{29}$ para los rumberos más mayores. Es en los cuerpos (y sus inscripciones étnico-raciales, de género y edad), que los orishas (o deidades de la Regla de Ocha) pueden ser performáticamente sugeridos durante las largas sesiones públicas (y turísticas) de rumba que, cautelosamente, acontecen escindidas de las prácticas concretas de la religión de origen yoruba. Entre los sitios y prácticas de rumba inventariadas para el expediente presentado frente a UNESCO, sin embargo, en un cincuenta por ciento las casas de rumba declaradas se corresponden con templos o cabildos religiosos que para las fechas "de santo" realizan toques de rumba. Los instrumentos musicales

\footnotetext{
${ }^{28}$ Esta tendencia busca posicionar a "la cultura" como principal fuente de ingresos para artistas, gestores, y también grupos étnicos.

${ }^{29}$ Es un estilo de rumba más lenta, de movimientos más cadenciosos, cuyos bailarines destacados suelen ser usualmente mayores.
} 
inventariados se corresponden asimismo con la rumba y sus variantes según poblado, quedando por fuera los toques de cajón $^{30}$ (utilizados para el culto a los antepasados $\operatorname{congos}^{31}$ ) y los tambores de religión yoruba o tambores batá. Según los artistas (y referentes religiosos) que llevaron adelante la postulación, la Regla de Ocha o Santería no alcanza los requisitos para su patrimonialización dado que los estándares religiosos no coinciden con los valores promovidos por la UNESCO en su adhesión a la Declaración Universal de los Derechos del Animal $^{32}$. A partir de la misma, se deduce que los seres humanos sacrifican animales o interrumpen su vida solo cuando media una necesidad (como la alimentaria, razón por la cual, a pesar de esta declaratoria, el consumo de carne se extiende a lo largo del mundo). Desde una lectura secular, la necesidad alimentaria no se correspondería ni con los orishas ni con los antepasados ${ }^{33}$. Por esta razón, en 2006 fue inscripto por Nigeria el Oráculo de Ifá y no la totalidad de las prácticas religiosas que en Cuba se asocian al mismo -lo que es disímil entre África y América-. Concretamente, bajo los estándares de la patrimonialización, las prácticas de rumba son secularizadas.

Para el caso cubano, según versan los trabajos de Johnson y Palmié (2018), la percepción de la religión de origen africano en Cuba como "superstición" o "idolatría" tiene ya sus antecedentes en la definición que las autoridades eclesiásticas y seculares coloniales realizaban sobre las prácticas religiosas que tenían los esclavos y libertos africanos. Así “aparecen en el registro colonial incluso antes de que se instalara la institución formal de la Santa Inquisición en México en 1571 y, más tarde, en Lima y Cartagena de Indias" (JOHNSON Y PALMIÉ, 2018 p.514). Los autores explican las limitaciones y las posibilidades que tuvieron las religiones de origen africano para desarrollarse en Cuba en tanto "surgidas después de la abolición de la esclavitud y durante el siglo XX por efecto de las leyes, las ciencias sociales y el Estado nación". Y argumentan que "ni el calificativo "afro" como tampoco el concepto de "religión" deben tomarse al pie de la letra cuando se consideran tradiciones que ubican sus fuentes de legitimidad, autenticidad y eficacia ritual en nociones de origen

\footnotetext{
${ }^{30}$ Tambores cónicos de madera que asemejan a las tumbadoras a la vez que simulan el material del cajón del muerto.

${ }^{31}$ Son prácticas vinculadas a los antepasados y los muertos que en cada contexto nacional regional adquieren características y sincretismos disímiles.

32 La Declaración Universal de los Derechos del Animal ( 1978) cuenta con el aval de ONU y UNESCO.

${ }^{33}$ La Regla de Ocha e Ifá incluye el sacrificio de pequeños animales, eventualmente, en sus prácticas religiosas.
} 
africano". La cultura popular, sin embargo, siempre saltea estas diligencias a base de sincretismos, intersticios y estéticas híbridas.

Muy a pesar de la escasa extensión que tienen en Cuba las redes sociales habilitadas a partir de las nuevas tecnologías, entre las nuevas generaciones juveniles el uso es extendido. Entre jóvenes cubanos, las músicas producidas en contextos tradicionales de folklor -y entre ellas, las que conforman un repertorio religioso- se presentan en continuidad con los géneros musicales centroamericanos, con la salsa, con el rap e incluso también con el reggaetón. El uso medido de dispositivos celulares limita pero no inhibe a los jóvenes cubanos del uso y el acceso a los medios y las mediaciones que las nuevas tecnologías y artefactos posibilitan, facilitando no solo el consumo sino la producción cultural. Este es el caso de El Huérfano, músico "rapero" socialmente blanco de origen cubano que reside en España (Islas Canarias) y se autopercibe como "afrocubano" en base a su inscripción religiosa y no a su fenotipo racial. Sus video clips encierran tanto estéticas alusivas al complejo religioso conocido como Regla de Ocha e Ifá, como sentidos de ser (afro)cubano para quienes están en la experiencia religiosa dentro o fuera de la isla:

Yo soy afrocubano,

mi cuna religiosa siempre ha sido Cuba, donde el amarillo y verde representa a Orula, eso es lo que vivo yo.

Por eso soy afrocubano, la vocación perfecta de nuestra cultura, desde la esclavitud hasta la última luna, yo te llevo en el corazón.

Por todos los que transportaron su ashé, por todos los esclavos que sincretizaron su fé, que adaptaron sus creencias enfrentando adversidades ahora somos lo que somos por mucho que pase.

Le doy gracias a Shangó por sentenciar mi guerra, a Ogum, mi padre, gracias por nunca dejar que pierda, mis caminos abiertos si así lo decide Eleggua por muchos que quieran interponerme piedras.

Cuando la tormenta acaba está la calma, me dijo Iansá, "aquellos que jueguen contigo visitan mi casa".

Convierte lo dulce en más dulce aún, librándome me da aguas mansas, de eso ya se encarga Oshun. 
Dame solo papinú eso me dijo yemya [Yemanja],

donde tu me necesites estaré dispuesta, para cada situación tú tendrás mi influencia recuerda que el mundo tiene más agua que tierra.

Para los afrocubanos más involucrados con su entorno, la patrimonialización de la rumba constituye un proceso de agencia que pudo alcanzar resultados aún bajo la estricta sujeción al régimen político y secular de la isla. En tanto las gestiones para la patrimonialización y el principal impulso para la misma estuvo dado por artistas afrocubanos con residencia europea, en la postulación misma se produce una inversión o subversión de las normas en relación con los procedimientos estatales y gubernamentales que son usuales e intrínsecos al Patrimonio Intangible internacionalmente regido (UNESCO, 2003). En las y los performers y en los sentidos de afrocubanía que se atribuyen, se subvierten las lógicas usuales de la "raza" en tanto la etnicidad es garantida por la inscripción religiosa.

\section{“(Re)imaginando a África" en clave no binaria desde el carnaval uruguayo}

El caso uruguayo nos permite contrastar estos dos procesos de patrimonialización caribeños con los dados en el Cono Sur, para volver a revisar la versatilidad de las performances afrolatinaomericanas en su ingreso a los mandatos del "desarrollo" y a los desafíos del reconocimiento establecidos en la normatización del patrimonio inmaterial. Son privilegiadamente los desfiles de tambores de candombe los que han caracterizado la historia performática de este colectivo poblacional afrouruguayo en las calles de la ciudad capital de Montevideo. El caso nos presenta otra tensión ya que la "lucha" política y la reproducción de "la cultura ancestral" no necesariamente siempre se ven disociadas de la reproducción de los estereotipos raciales y de género, lo que en el candombe ocurre mediante la sujeción de los cuerpos y las performances al reglamento del Desfile de Llamadas y/o al reglamento del carnaval.

La declaratoria del candombe como Patrimonio Inmaterial de la Humanidad (2009) ha sido producto del arduo proceso de politización que, desde los 
últimos años que caracterizaron a la dictadura, han llevado adelante sobre todo activistas afrouruguayas y afrouruguayos en búsqueda de la legitimación de su acervo y del reconocimiento social y sociodemográfico que revela en los afrodescendientes a una parte insoslayable de la nación uruguaya (ANDREWS, 2011; FERREIRA, 1999, 2003). Los criterios de estandarización cultural, sin embargo, han tenido lugar desde mediados del siglo XX con la inserción de la categoría de Sociedades de Negros y Lubolos al carnaval. El carnaval uruguayo, aunque en mucho menor medida que el carnaval brasileño (o que el Carnaval de Río de Janeiro desde hace décadas desarrollado como industria), moviliza economías dolarizadas y reglamentos estéticos que en algunas circunstancias parecieran atentar contra la "conciencia negra" de los propios afrouruguayos de sectores más populares y periféricos (PARODY, 2017 b). Es en este espacio donde, contra la impronta crítica que presentan las murgas montevideanas en el Teatro de Verano, las performances afrouruguayas parecieran ceñirse a guiones estereotipados que privilegiadamente los remiten a la relatoría esclavista de sello negrista (PARODY, 2017 b).

Cuerpos racializados y sexo-generizados tienen un lugar central en las "Sociedades de Negros y Lubolos" que protagonizan el Desfile de Llamadas. El carnaval es, sin embargo, el producto agentivo por excelencia del colectivo afrouruguayo que, a mediados del siglo $\mathrm{XX}$ y en pos de una justicia distributiva, pudo alcanzar su inclusión creando la categoría de Sociedades de Negros y Lubolos para competir por premios monetarios y asimismo insertar "dueños" directores de comparsas en la DAECPU (Directores Asociados de Espectáculos Carnavalescos Populares del Uruguay). Es decir que, el mismo dispositivo masivo que facilita la irrupción legitimada de la cultura negra en el espacio público, es el que puede tender a mantener también los estereotipos étnico-raciales a la orden del día, incluso con representaciones propuestas por los propios colectivos performáticos donde el África es asociada a una imaginería selváticas y animalizada (ANDREWS, 2011). En este mismo dispositivo masivo, organizaciones de activistas despliegan consignas con las que favorecer la sensibilización de la sociedad uruguaya en torno de -por ejemplo- la no discriminación y/o el Decenio de las y los Afrodescendientes (ONU, 2014-2024). Desmarcándose de la dicotomía que observara Cunha (2001) para el caso brasileño, el movimiento político afrouruguayo articula la variable cultural como herramienta para la "lucha" y reivindicación o acceso a derechos (FERREIRA, 2003; PARODY, 2016). 
¿Con qué elementos entonces es que el carnaval, más allá de las implicancias de su movilización de economías, consigue fijar identidades racializadas y generizadas que en las performances son asumidas en el cuerpo?

Más allá de la "tradición" que es memoria corporal activa de las agrupaciones, existe un Reglamento del Desfile de Llamadas que la intendencia de Montevideo emite anualmente. En el mismo se fijan las pautas para el correcto discurrir (organizativo y estético) del evento. Tal como recogen los libros de los folkloristas y cientistas (CARÁMBULA, 1966; ORTIZ ODERIGO, ANDREWS, 2011), y desde hace décadas puede observarse en los Desfiles de Llamadas y otros eventos a cargo de las comparsas y/o artistas afrouruguayos y afrouruguayas, la mama vieja y el gramillero, el escobero, bailarín y bailarina (entre ellos destaques y vedette), constituyen los "personajes" constitutivos de las comparsas. Sus orígenes suelen resultar controvertidos (ANDREWS, 2011; AYESTARÁN, 1963), pero es claro que sus performances responden a aquellos procesos caracterizados por lo que Glissant (2019) denominó como poética de la relación (en este caso, entre elementos africanos e hispanoamericanos del Montevideo colonial y tardo colonial, nunca fijados sino en un estar-siendo).

Durante los últimos años, las controversias se han presentado sobre todo en relación al desempeño del bailarín masculino o varón, precisamente por los debates a los que nuestras sociedades asisten en materia de género y diversidad sexual $^{34}$ (ÁLVAREZ NAZARENO, 2019). Estas problemáticas también se habían presentado anteriormente en la desaprobación social de la dedicación de las mujeres a la ejecución del tambor -quienes se sobrentendía debían mantenerse abocadas al baile- lo que en la actualidad es más aceptado en comparsas íntegramente formadas por mujeres como ejecutoras de tambor.

Estas correspondencias sexo-genéricas entre tambor y masculinidad por un lado (FERREIRA, 1999), y danza y femineidad por otro (RODRÍGUEZ, 2010), resultan constitutivas en la "tradición" afrouruguaya pero no imposibles de ser revisadas (ÁLVAREZ NAZARENO, 2019). Lo que aquí deseo aportar al respecto, entonces, remite menos al desarrollo de las performances en sí mismas y más a su contexto de producción/regulación mediante reglamentos. Según el reglamento para la participación de una comparsa en el Desfile de Llamadas de 2020 organizado por la intendencia de Montevideo, al momento de inscribir a los componentes, se deberá cumplir -sin excepciones- con los requisitos de presentar como mínimo cuarenta tamborileros (con un máximo permitido de

\footnotetext{
${ }^{34}$ Durante muchos años, participando como bailarina o tamborilera, o acompañando grupos a diferentes Desfiles de Llamadas en la capital o el interior del Uruguay, he vivenciado apreciaciones entre los miembros de los jurados referidas a la condición de sexo-género del bailarín.
} 
setenta), una vedette, un bailarín, un portaestandarte, cuatro portabanderas (más las alegorías como medialuna y estrellas), un escobero, dos gramilleros, dos mamas viejas, y un cuerpo de baile de quince integrantes. El total de la comparsa se elevaba así a un mínimo de setenta componentes y un máximo de ciento cincuenta componentes totales. Bajo ningún concepto, "por el buen resultado del espectáculo", se habilita la participación de comparsas que no cumplen con estos requisitos establecidos y por ello se hace dejar constancia de los mismos en el momento de la inscripción en el que el director debe adjuntar las fichas declaratorias con cédula de identidad de todas y todos los integrantes. Si una comparsa no cumple con los requisitos establecidos puede tanto quedar descalificada como tener adjudicados "puntos a descuento" que interferirán en el premio económico (individual y colectivo) que puede recibir la agrupación según desempeño. Por el artículo 11 de dicho reglamento, el jurado otorga puntuación por "rubro ...siempre considerando la esencia de la expresión cultural del candombe", siendo los mismos: setenta puntos cada jurado por el desempeño del grupo de tambores (trescientos cincuenta puntos máximos); veinte puntos cada jurado por el cuerpo de baile (en el que "los movimientos coreográficos que puedan presentarse serán considerados en la medida en que respeten esa esencia"), veinte puntos por cada jurado como máximo por los desplazamientos, quince puntos por cada jurado para los "personajes típicos" (sobre los que se evalúa la danza e interpretación del escobero, mama vieja y gramillero) lo que implica un total nominal del rubro de doscientos setenta y cinco puntos -de lo que se deduce que una comparsa puede quedar descalificada o debe volver a concursar al año siguiente para poder participar por mal desempeño en este rubro-. Los personajes típicos tienen además diez puntos posibles de ser otorgados por cada jurado, en lo que califica el vestuario y la caracterización según "la fidelidad a la esencia de los personajes y el arte en su presentación estética". De esta forma, la mejor cuerda de tambores, el mejor cuerpo de baile, el mejor cuadro de personajes típicos, el mejor cuadro de alegorías o trofeos, y la mejor vedette y el mejor bailarín (quienes, como la mamá vieja y el gramillero, bailan juntos), reciben un premio en dinero cuyo promedio oscila entre los U\$S 1000 para personas individuales, siendo de resaltar que cualquier mal desempeño de cada integrante puede afectar al premio monetario general de la comparsa en su conjunto.

La patrimonialización del candombe se llevó adelante precisamente, entre otros motivos, para contrarrestar los efectos de la espectacularización de esta expresión. Aun así, deja al colectivo afrouruguayo frente al desafío de "mantener la tradición" y a la vez horadarla en función de los principios de 
inclusión que las heterogeneidades del sexo-género (y no solo las interseccionalidades del género y la raza) requieren en estos nuevos tiempos que nos asisten.

\section{Conclusiones}

En el presente trabajo, producto de un primer avance de investigación doctoral en inicio, pude dar cuenta de cómo aún bajo regímenes de gobierno disímiles, cuerpo-raza y performances se articulan de similares maneras para responder a políticas culturales de corte global que afianzan las construcciones de otredad previas y situadas en las que afrocolombianos/as, afrocubanos/as y afrouruguayos/as se constituyen como sujetos. En una apuesta por la justicia redistributiva, la legitimación y el reconocimiento, los grupos comunitarios prestan su consentimiento a los Estados (y/o viceversa, tal como el caso cubano nos muestra) para pasar luego a instrumentar junto al mismo una serie de medidas que garanticen la proliferación de repertorios y la ampliación de archivos (Taylor, 2015) -es decir, en términos de la convención, proceden a "salvaguardar" las performances en cuestión-.

Algunos de los mecanismos que se activan bajo los estándares del patrimonio, parecieran atentar contra la dimensión comunal-performática que estas expresiones como la rumba, el candombe, o el bullerengue y el lumbalú aún detentan para quienes configuran su lazo social con el mundo en la performance. Para todas/os quienes habitan sus sentidos de negritud/negridad/afrodescendencia en diáspora, la performance posibilita sentidos corporizados de ser-en-el-mundo. Es en los intersticios dados entre esta dimensión comunal y los puentes tendidos tanto en función del reconocimiento como de la redistribución que los grupos afrodescendientes consiguen subvertir el orden dado, aún "en la casa del amo" pero con gestos propios. Sin embargo, tal como nos demuestran algunos regímenes de carnaval o las nuevas estrategias de la economía global, estas performances no siempre ni bajo cualquier condición consiguen cuestionar los regímenes hegemónicos sino que, muchas veces en el juego de la ambigüedad, pueden colaborar con los mismos. De manera específica, sectores poblacionales signados por la "raza" parecen cobrar visibilidad para la agenda estatal teniendo a "la cultura" como garantía. En tanto, en el terreno de los sentidos corporeizados de enunciabilidad y/o en los regímenes de corporalidad situados (RESTREPO, 2012), se dirimen sus estatus de humanidad (y ciudadanía) posible. 
Me pregunto entonces, frente a las patrimonializaciones ¿cuáles son las subversiones, agencias y sujeciones que acontecen en este tipo de procesos donde espacios del ritual quedan en una nueva vitrina internacional? ¿Cómo se articula 'el patrimonio' a los diferentes regímenes de la diferencia en el marco de los contextos políticos dados por los disímiles multiculturalismos locales, qué tipo de economías inyecta y cómo esto es traducido en nuevas encarnaduras? Y, finalmente, ¿cuáles son las condiciones que posibilitan a los grupos desmarcarse de los mandatos para inaugurar nuevas formas corporeizadas de acción? Cuba en particular, se dirime entre desmarcarse de la cuestión racial/racializada, subsumirse a versiones ya conocidas de multiculturalismo, o fundar procesos capaces de articular los derechos de los grupos históricamente negados y con acceso desigual (tal como afrodescendientes, y LGTBIQ). El caso colombiano pudo mostrarnos como cuerpo y habla se imbrican en la construcción de una etnicidad políticamente correcta, en tanto en búsqueda de una justicia redistributiva se desdibujan los límites entre el empoderamiento y la agencia de las mujeres y su reducción a fetiches en el circuito turístico. En tanto Cuba y Colombia aspiran en algunas de sus versiones patrimonialistas al turismo de base cultural, ambas pueden tener en la etnicidad el fetiche garantido, como ambas pueden cuestionar el lugar de lo redistributivo tras sus versiones nacionales (neoliberal y socialista) de multiculturalismo. Con tales antecedentes derivados del carnaval, en Uruguay los desafíos redistributivos ceden lugar al cuestionamiento de los valores sexo-genéricos implícitos en las performances legitimadas por la patrimonialización. Este avance acontece gracias a que la equidad y la lucha por los derechos ha sido asumida por el activismo afrouruguayo alcanzando instancias de avance estadístico y jurídico, proyectando horizontes de mayor justicia para los afrouruguayos. Las marcaciones y sujeciones, como agencias y subversiones, en todos los casos atraviesan todos los planos manifiestos del discurso (lingüístico, jurídico, y performático-corporeizado).

Cual "matriz de razón práctica" (FOUCAULT, 1988), en las performances afrolatinoamericanas y caribeñas patrimonializadas se asumen formas autorizadas de ser negros/as donde la sujeción a la norma se nos presenta como "biológicamente dada" frente a una agencia política transformadora que, además de resignificaciones y procesos agentivos, muchas veces requiere de subversiones de género, de clase, y de inscripción racial, nacional o religiosa. Siguiendo estas nociones en Butler (2007), nos es factible estimar que la repetición (o mímesis) sobre la que se asienta todo proceso de performatividad nunca es "repetición de lo mismo" sino desplazamiento: en su juego de 
estabilidad/inestabilidad, las performances afrolatinoamericanas siempre dejan abierta la posibilidad para las transformaciones, nuevas poiesis, fugas e intersticios. En tales procesos de largo aliento, "no es extraño, incluso, encontrarse con abiertos reduccionismos biodiversalistas y culturalistas esgrimidos a nombre de sectores subalterizados y su bienestar" (RESTREPO, 2003, p. 197). A la vez, puede darse con posibilidades agentivas y subversivas acaecidas en medio de estos procesos performáticos signados por la corporalidad (QUINTERO RIVERA, 2009). En todo caso, en este artículo me he inclinado por la ambigüedad que revisten estos procesos que de antemano tanto pueden garantizar reproducciones como desmarcaciones según el poder logre (o no) esconder sus mecanismos (FOUCAULT, 2006) y los actores sociales consigan (o no) organizar "la cultura" en favor de los avances políticos. En medio de estos factores, la economía se presenta como una variable que urge analizar.

\section{Bibliografía citada}

AGUDEL0, Carlos

(2005). Retos del multiculturalismo en Colombia. Política y poblaciones negras. Medellín, Ed. IEPRI-IRD-ICANH-La Carreta.

(2019) Paradojas de la inclusión de los afrodescendientes y el giro multicultural en América Latina. Cuadernos Inter.c.a.mbio sobre Centroamérica y el Caribe, vol. 16, núm. $2,[\mathrm{~s} / \mathrm{d}$.

ALÉN, Olavo

(2016) Haciendo son en otro jazz. Conferencia de cierre del XII Congreso de la IASPM-AL, Casa de las Américas, La Habana, viernes 11 de Marzo

ÁLVAREZ NAZARENO, Carlos

(2019) Cultura afrouruguaya: el candombe y la comparsa como espacios de Resistencia". En Campoalegre Septien, Rosa y Ocoró Loango, Anny; Afrodescendencias y Contrahegemonías. Desafiando al decenio. Buenos Aires, CLACSO, 359-374.

ANDREWS, George R.

(2011) Negros en la nación blanca: historia de los afrouruguayos, 1830-2010. Montevideo, Linardi y Risso.
ARIAS, Julio \& RESTREP0, Eduardo.

(2010). Historizando raza: propuestas conceptuales y metodológicas. Crítica y Emancipación, (3), 45-64.

AROCHA, Jaime

(1999) Ombligados de Ananse: hilos ancestrales y modernos en el Pacífico colombiano. Santa $\mathrm{Fe}$ de Bogotá, Universidad Nacional de Colombia.

(2004) (comp.) Utopía para los excluidos. El multiculturalismo en África y América Latina, Bogotá, Universidad Nacional de ColombiaCentro de Estudios Sociales.

AUSTIN, John.

(1956) Emisiones realizativas. En: Valdés; $L a$ búsqueda del significado. Madrid, Tecnos, pág. 419-430.

(1962) Cómo hacer cosas con palabras. Paidos, Barcelona.

AYESTARÁN, Lauro

(1953). La música en el Uruguay. Montevideo, SODRE.

(1967). El folklore musical uruguayo. Montevideo, Arca. 
BIANCIOTTI, María Celeste \& ORTECH0, Mariana

(2013) La noción de performance y su potencialidad epistemológica en el hacer científico social contemporáneo. Tabula Rasa, núm. 19, julio-diciembre, pág. 119-137.

BLACKING, John.

(1995) Music, Culture and Experience. Chicago and London, The University of Chicago Press.

BOCAREJ0, Diana \& RESTREPO, Eduardo

(2011) Introducción. Hacia una crítica del multiculturalismo en Colombia. Revista Colombiana de Antropología, Volumen 47 (2), julio-diciembre, pág. 7-13.

BUTLER, Judith

(2005) Cuerpos que importan. Sobre los límites materiales y discursivos del "sexo". Buenos Aires, Paidós.

(2007) El género en disputa. El feminismo y la subversión de la identidad. Barcelona, Paidós.

CAGGIANO, Sergio

(2015) Imaginarios racializados y clasificación social: retos para el análisis cultural (y pistas para evitar una deriva decolonial esencialista). Cuadernos Intercambio sobre Centroamérica y el Caribe, Vol. 12, No. 2 Julio-Diciembre, pág. 121-152.

CAMPOALEGRE SEPTIEN, Rosa

(2019) Cuba y los desafíos de la lucha contra el racismo: Hacia futuros compartidos. Cuban Studies, Nro 48, pág. 71-89.

CARPENTIER, Alejo

(1933) ¡Écue-Yamba-O! Madrid, Editorial España.

CARÁMBULA, Rubén

(1966) El Candombe. Danza ritual pantomímica del folklore Afro-Rioplatense. BsAs, Ricordi Americana S.A.

CARVALHO NETO, Paulo de

(1955). La obra afro-uruguaya de Ildefonso Pereda Valdés: ensayo de crítica de antropología cultural. Montevideo, Centro de Estudios Folklóricos del Uruguay.
(1971) Estudios afros. Brasil, Paraguay, Uruguay, Ecuador. Caracas, Instituto de Antropología e Historia.

CASTRO, Fidel

(1959). Quizás el más difícil de todos los problemas: la discriminación racial. Disponible en:

http://www.granma.cu/granmad/secciones/fi del_en_1959/art-048.html . Recuperado el 9 Mayo de 2021.

(2001). Discurso en la Sesión Plenaria de la Conferencia Mundial contra el Racismo, la Discriminación Racial, la Xenofobia y las Formas Conexas de Intolerancia, Durban, Sudáfrica. Disponible en: http://www.cuba.cu/gobierno/discursos/200 1/esp/f010901e.html . Recuperado el 9 Mayo de 2021.

CASTRO-GÓMEZ, Santiago \& GROSFOGUEL, Ramón (eds.)

(2007). El giro decolonial. Reflexiones para una diversidad epistémica más allá del capitalismo global. Bogotá, Iesco-Pensar-Siglo del Hombre Editores.

CITRO, Silvia; PODHAJCER, Adil; ROA, Luz \& RODRÍGUEZ, Manuela

(2020) Investigar desde la performance: Un abordaje comparativo del teatro etnográfico y las intervenciones performáticas participativas. Antropología Experimental, (20), 13-24.

\section{CLACSO}

(2019). Más allá del decenio internacional de los pueblos afrodescendientes. Disponible en: https://www.clacso.org/mas-alla-deldecenio-internacional-de-los-pueblosafrodescendientes/. Recuperado el 7 de Mayo de 2020.

COMAROFF, John \& COMAROFF, Jean

(2011) Etnicidad S.A. Buenos Aires, Ediciones Katz.

CUBA VEGA, Lidia

(2019). Políticas para la equidad racial. Retos en el contexto cubano actual. Estudios del Desarrollo Social, vol.7, n.2, s/p. 
CUNIN, Elizabeth

(2006). Escapate a un mundo...fuera de este mundo: turismo, globalización y alteridad. Los cruceros por el Caribe en Cartagena de Indias (Colombia). Boletín de Antropología, año/vol. 20, número 037, pág. 131-151.

DE LA FUENTE, Alejandro \& ANDREWS, George (2018) Estudios afrolatinoamericanos : una introducción. Ciudad Autónoma de Buenos Aires, CLACSO ; Massachusets, Afro Latin American Researcher Institute, Harvard University.

ESCOBAR, Arturo

(1994) El desarrollo sostenible. Realidad y mitos. Esteros. (3-4), pág. 15-21.

(2003). Mundos y conocimientos de otro modo: el programa de investigación de modernidad/colonialidad Latinoamericano. Tabula Rasa, (1), pág. 51-86.

FOUCAULT, Michel

(2006) Historia de la sexualidad: La voluntad del saber. Buenos Aires: Siglo XXI.

FRIEDEMANN, Nina

(1979) Ma Ngombe: guerreros y ganaderos en Palenque. Colombia, Editorial Carlos Valencia.

FRIEDEMANN, Nina \& PATIÑO, Carlos

(1983) Lengua y Sociedad en el Palenque de San Basilio. Bogotá, Instituto Caro y Cuervo.

FRIEDEMANN, Nina S. de y AROCHA, Jaime

(1982) Herederos del Jaguar y la Anaconda. Bogotá, Carlos Valencia Editores.

GLISSANT, Edouard

(2019) Poética de la relación. Quilmes, Ediciones UNQ.

GUILLÉN, Nicolás

(1931) Sóngoro Cosongo. La Habana, Editorial Páginas.

HALL, Stuart

(2010) El espectáculo del ‘Otro'. En: Stuart Hall, Sin garantías. Trayectorias y problemáticas en estudios culturales. pp. 419-446. PopayánLima-Quito: Envión Editores-IEP- Instituto Pensar-Universidad Andina Simón Bolívar.
HANNERZ, Ulf

(1998) Conexiones transnacionales. Cultura, gente, lugares. Valencia, Editorial Frónesis.

HERSKOVITS, Melville

(1928) The American Negro. Nueva York, AA Knopf.

(1930) La antropometría del negro americano. Nueva York, Columbia University Press.

(1941) The Myth of the Negro. Nueva York, Harpers.

JACKSON, Michael

(1996) Things as They are ('Introduction'). Bloomington and Indianapolis, Indiana University Press.

MANZANARES BLANCO, Noel

(2020) Racismo en Cuba: crítica a sus críticos. Revista Internacional de Pensamiento PolíticoI Época - Vol. 15, pág. 371-386

\section{MORALES DOMÍNGUEZ, Esteban}

(2002) Un modelo para el análisis de la problemática racial cubana contemporánea. CATAURO. Revista cubana de antropología, Año 4, Nro 6.

ORTIZ, Fernando

(1921) Los cabildos afrocubanos. La Habana, Imprenta La Universal.

(1924) Glosario de afronegrismos. La Habana, Imprenta El Siglo XX.

(1940) Contrapunteo cubano del tabaco y del azúcar

(1985 [1951]) Los bailes y el teatro de los negros en el folklore de Cuba. La Habana, Editorial Letras Cubanas.

(2015) Epifanía de la mulatez. Historia y poesía. La Habana, Fundación Fernando Ortiz.

ORTIZ ODERIG0, Néstor

(1968) África en el Río de la Plata. Buenos Aires, $\mathrm{s} / \mathrm{d}$.

(1969) Calunga! Croquis del candombe. Buenos Aires, Eudeba. 
PARODY, Viviana

(2017 a) 'Danzando en el umbral': del sujeto intersticial y su (im)posibilidad en un campo racializado de estudios 'afrodescendientes' en Argentina. Intersticios de la política y la cultura. Intervenciones latinoamericanas, Año 6, Vol. 12, pág. 119-145.

(2017 b) Balances y perspectivas de los estudios afrodescendientes en el Uruguay. Tabula Rasa, Nro.27, pág.103-128.

PEIRAN0, Mariza (org.).

(2001). O dito e o feito: Ensaios de Antropologia dos Rituais. Rio de Janeiro, Realume Dumará.

VOLPATO PERBELLINI, Tristano

(2008). Cuba multicultural: una reconstrucción del concepto de multiculturalismo para el análisis de la sociedad cubana. Tesis de Maestría en Ciencias Sociales presentada a la FLACSO - Sede Académica de México. México.

PEREDA VALDÉS, Ildefonso

(1937) El negro rioplatense y otros ensayos. Montevideo, Claudio García y Cia. Editores

(1965) El negro en el Uruguay: pasado y presente. Montevideo, Instituto Histórico y Geográfico del Uruguay.

QUINTERO RIVERA, Ángel

(2009) Cuerpo y cultura: las músicas "mulatas" $y$ la subversión del baile. Madrid, Iberoamericana-Vervuert.

RESTREP0, Eduardo

(2003). Entre arácnidas deidades y leones africanos. Contribución al debate de un enfoque afroamericanista en Colombia. Tabula Rasa, Vol.1, pág. 87-123.

(2004). Políticas de la teoría y dilemas de los estudios de las colombias negras. Popayán, Editorial Universidad del Cauca.

(2010). Cuerpos racializados. Revista Javeriana, 146 (770), pág. 16-23.

RODRÍGUEZ, Manuela

(2010) "Representando a mi raza". Los cuerpos femeninos afrodescendientes en el candombe. En: Citro, Silvia (Coord.); Cuerpos plurales.
Antropología de y desde los Cuerpos. Buenos Aires, Biblio.

SCHECHNER, Richard.

(1985) Between Theater and Anthropology. Philadelphia, University of Pennsylvania.

(2000) Performance. Teoría y prácticas interculturales. Buenos Aires, Libros del RojasUBA.

SEARLE, Jhon.

(1990). Actos de habla: ensayo de filosofía del lenguaje. Madrid, Cátedra.

TURNER, Víctor.

(2002). La antropología del performance. En: Geist (comp.); Antropología del ritual. México, Instituto Nacional de Antropología e Historia, Pág. 103-144.

VALLE, Mónica \& MARTÍNEZ, Julia

(2018) Cuando las culturas se escriben sobre el cuerpo de las mujeres.: aspectos antropológicos y feministas sobre la vestimenta religiosa. En: Fernando, Del Barrio Natalia, Hellman Jacqueline, and Regueiro Raquel ; Antropología Cultural Del Vestido: Perspectivas Sobre El Burkini, Madrid: Dykinson.

ZAPATA OLIVELLA, Manuel

(1963) Chambacú, corral de negros. La Habana, Casa de las Américas.

(1967) Aportes materiales y sicoafectivos del negro en el folklore colombiano. Boletín Cultural. Año 10, Nro 6.

(1977) Identidad del negro en América Latina. Cali, Seminario Cultural El Pueblo.

(1983) Changó el gran putas. Bogotá, Editorial Oveja Negra.

\section{Recebido em}

julho de 2021

\section{Aprovado em}

dezembro de 2021 